\title{
A MULTICRITERIA DESCRIPTION OF RULES FOR PUBLIC PROCUREMENT
}

\author{
MALIŠA ŽIŽOVIĆ ${ }^{1,2}$, MILUTIN ŽIVKOVIĆ ${ }^{3 *}$ \\ ${ }^{1}$ University of Singidunum- Belgrade, Faculty of Business - Valjevo, Serbia \\ ${ }^{2}$ University of Kragujevac FTS - Čačak, Serbia \\ ${ }^{3}$ High Technical Mechanical School Trstenik, Serbia
}

\begin{abstract}
At an announced tender of a contracting party, in the processes of public procurement of goods or services, a method of decision-making follows after interested bidders submit bids. Such method of choice is characteristic for all business systems with majority share of state capital. Methods of decision-making come down to selecting the best bids, because mistakes in the selection should be excluded. However, in practice, the problems of a wrong choice are manifested in dissatisfaction of the bidders. The problem then causes a delay in the procurement process, and often the retrial. In order to prevent this from happening authors of this paper suggest a somewhat different methodologies in selecting the most advantageous tender to the contracting authorities. The proposed method will be the case of the of Parking service (PC) from Belgrade (service of overhaul of the devices) will show a possible way of selecting the best alternative bids, taking into account previously adopted criteria.
\end{abstract}

Keywords: public procurement, decision-making, criterion, bid, alternative, methodology

\section{INTRODUCTION}

All procurements in the public and state sector, due to potential abuse, are strictly defined by the law on public procurement. In the procedures of public procurements generally occur problems when formulating or how to make a characterization of criteria for evaluation of submitted bids. No less important is the only implementation of the submitted evaluation process, as well as the selection of the best bidder. Defining criteria presents a selection from the plurality of options, of certain criteria, which are supposed to be of the utmost importance for the specific public procurement. Character of selected criteria affects the determination of the importance of their mutual relationships. In many papers, which can be found in the literature, the weight of criteria is given with the matrix pairs comparing the relative importance of relationship of the criteria or linguistic statements or with their combination.

The authors of this paper through the papers, presented at international scientific meetings, tried to contribute to this complex problem. It should be noted that the law on public procurements is usually the modified law with correspondence of new articles or modifying the existing ones. All this is aimed at its highest possible transparency and to correct identified deficiencies.

\footnotetext{
* Corresponding author, email: milutinzivkovicts@gmail.com

(C) 2016 Alma Mater Publishing House
} 


\section{SOMETHING ON PUBLIC PROCUREMENTS IN SERBIA AND HOW TO ELIMINATE FAILURES IN SELECTION}

Public procurements, by definition, are all actions that state-owned enterprises, as well as all public companies in order to function properly and performing the tasks for which they are registered, claim various services or procurements from others, outside of that particular company.

In socialist economies in which there were no private companies there wasn't the problem of public procurements because all operations (services, procurements, ) were planned either by government or party (in each such country, there was only one party) authorities. If something had to be purchased from abroad it had been carried out by the special state companies authorized for that job.

How the former Yugoslavia (and thus Serbia) had a system where in addition to state and private enterprises existed (mainly from the so-called category of small business), this problem has existed but in a very small form because all major purchases were planned and controlled by state (party). Yet for these small "public procurements" among the former owners of private enterprises have prevailed great interest and there have been demands to regulate this field and make it "transparent".

After the "democratic changes" and the privatization of a large number of business entities still remained a number of state-owned enterprises and for their procurements (public procurements), whether in terms of services, procurement and maintenance of technical means... are interested in any other companies for these services, procurements... because the funds for this activity are provided by the state.

Due to the great interest of a large number of potential participants comes to media interest because almost always exist some complaints after the completion of a public procurement made by those who are not selected and the fact that objectively there is a possibility of various manipulations. As the procurement has become a daily occurrence, due to the large number of interested companies, and their needs and how each government seeks to represent itself in the best possible "light" so in all countries, "abandoned" from socialism made new laws related to this issue. In the Republic of Serbia, the law on public procurement is one of the most changed (modified) laws. The latest amendments to the Law came into force on 01.01.02016. (It can be said that this is the latest version of the law). Versions of this law can be seen on the website of the Government of the Republic of Serbia, [1-3] multicriteria. There are several publication where decision making methods contributed to public procurement operations [7-17].

In papers [1] and [2] the authors have analyzed the implementation of the Law on Public Procurement and thereby have been manifested many wrong methodologies done by contraction parties in terms of multicriteria approach of this issue with a view to the simplest application of the law. Also, in paper [2] has been proposed and one possible multi-criteria methodology that is consistent with the method of multi-criteria analysis and that with a little patience and practice can be successfully applied in public procurement.

In this paper, the methodology described in [2] is amended and made even easier to use. Using this (or similar introduced) methodology it is possible to avoid one of the most commonly used methodology is essentially a multicriteria or a very simple and even more so, in some situations obviously provides poor results - lexicographical method of multi-criteria analysis. In this method is usual the first criteria of price that bidders sometimes so much "deflate" (of course at the expense of other criteria related to technical, financial,... characteristics) so even the legislator had to react and in the latest amendments to this law we have articles of ,unusually low price" which basically if accepted the bid with a higher price and in terms it does not stand, [2]!

\section{PROPOSAL OF NEW METHODOLOGY FOR EVALUATION OF PUBLIC PROCUREMENT}

In paper [2] the authors have proposed a methodology with which in the essence the multi-criteria can be evaluated the offered alternatives in a transparent manner and that the procedure does not reduce to the lexicographical method.

This methodology is here modified aimed to facilitate the procedure for the selection. It consists of the following steps:

- Step 1. 
Defines the criteria by which is being made selection.

- $\quad$ Step 2.

For each criterion are being defined the values with which the decision-making is very satisfactory.

- Step 3.

For each criterion are being defined the values that are acceptable to the decision-maker.

- $\quad$ Step 4.

For each criterion are being defined the values that are well acceptable to the decision-maker.

- $\quad$ Step 5.

For each criterion are being defined the values that are acceptable to the decision-maker.

- Step 6.

Per each criterion are defined the values that are hardly acceptable for the decision maker (below / above which is not going if the criterion of maximizing / minimizing type).

- $\quad$ Step 7.

Define the points awarded to the bid for value from step 2 to 6 and values within these steps for each criterion. This means that for each criterion is defined formula by means of which are determine the points for each criterion.

Steps from 2 to 7, relate to the criteria for which it is possible to define these values, respectively the decisionmaker believes it should be defined. If the decision-maker believes that under certain criteria, such as is the price those values will not or does not want to define - is not obliged to do so.

- Step 8.

Define the points that will give the value according to the criteria for which values from step 2 to 6 are not defined. In general, if the price is in question these points would be granted by a monotonous decreasing function of the price - if the price (service, parts, tools,...) increases the number of points decreases and vice versa.

- $\quad$ Step 9.

Based on pre-defined value the decision-maker could be defined how the one who submits a bid can be ranked in the following several zones (which are mutually disjunctive).

For example, zone 1: values according to criteria with which can be defined points of the decision-makers are very satisfied with the description (and above for max. criteria; i.e. below for min. criteria) and the total number of points, $\min Z_{1}$ according to the defined formulas.

Similarly could be defined the zone 2 , if the decision-maker considered that some individual bidders would remain outside the zone of the bid.

Each bidder would be obligated to "put" his into the zone to which it belongs and to write. Then, the decisionmaker, in principle, had an obligation after receiving the bid to check up whether the bids that have been marked as belonging to zones 1 and in this variant if there already has bids and only consider them as the ones from the lower zones are weaker! If there are no bids in zone 1 , then go to zone 2 and so on until the end!

So, when the decision-maker came to the highest zone in which there are bids then he within that zone makes a selection. The same can be accomplished in several steps:

- Step of selection 1: For each bid by the previous methodology determines the number of points and selects the bid that has the highest points (if it is a unique bid - the process is completed), otherwise it is going to.

- Step of selection 2: If two or more bids have the same number of points then only for them is performed a new choice so that some of the criteria (this is predefined) are omitted and is formed for this bid according to a set of criteria of the ranking list where the bid with the highest number of points is selected (again if this bid is by itself - if it is not the process continues).

$-\quad-\quad-$

$-\quad-\quad-$

$-(--10$ 
The penultimate step of choice: If it occurs it is usually only one main criterion if one bid is the best on this criterion - it is selected. And if not then we go on.

The penultimate step of choice: It is selected of multiple offers, which are the same in all the pre-defined selection criteria, choosing one that is first sent to the contracting party. If this cannot be established, or the same sent simultaneously then undertakes the selection by a method at random selection (out of a hat).

\section{THE POSSIBILITIES OF APPLICATION TO A REAL CASE}

There are several methods for selection of the most appropriate bid according to the adopted law on public procurement and the available papers and books that deal with this issue, [4-6].

The paper [1] analyzes the real example of public procurement, where it is shown that lexicographical choice is not good. This paper is the same case applied the proposed methodology and proved to be identical as a result of the selections in [1] or in multi-criteria methodology.

Example: This will give a brief description of the case of public procurement of the "Parking service" from Belgrade, which was consistent to conducted methodology given in the previous Table 1, [1]:

Table 1. Methodology of conducted public procurement

\begin{tabular}{|c|c|c|c|}
\hline \multicolumn{4}{|c|}{ CRITERIA } \\
\hline \multirow{2}{*}{ Bid } & $\mathrm{C}_{1}$ & $\mathrm{C}_{1}$ & $\mathrm{C}_{3}$ \\
\cline { 2 - 4 } & $\min$ & $\min$ & $\max$ \\
\hline $\mathrm{A}$ & 180 & 30 & 6 \\
\hline $\mathrm{B}$ & 168 & 10 & 9 \\
\hline $\mathrm{C}$ & 144 & 15 & 6 \\
\hline $\mathrm{D}$ & 168 & 60 & 9 \\
\hline
\end{tabular}

Note: The criterion price $\left(\min \mathrm{C}_{1}\right)$ in table $\mathrm{T}-1$ is given in dinars $(1.5$ Euro $=180 \mathrm{din})$

Since there is a small number of criteria and a small number of bidders in question is well to define interval shares of the bid, as it was stated in the previous chapter (2):

Criterion $\mathrm{C}_{1}$ : Price is nor defined by interval but is defined the number of points using a function:

$$
\begin{array}{ll}
> & \text { Criterion 1: } F(C)=\frac{\mathbf{1 6 0 0}}{\mathbf{C}} \\
> & \text { Criterion 2: } \mathrm{F}(\mathrm{v})=\frac{\mathbf{7 0}}{\mathbf{v}} \\
> & \text { Criterion 3: } \mathrm{F}(\mathrm{T})=\frac{\mathbf{T}^{\mathbf{2}}}{\mathbf{1 2}}
\end{array}
$$

This would define that zone 1 with the number of points above 20 for zone 2 is the number of points (15 to 20) and less than 15 points would be zone 3 .

It is not difficult to calculate that in zone 1 is the only bid $\mathrm{B}$, which would have been received. This is in the area of compliance with the multi-criteria analysis method where the order was, [1]. $\mathbf{B} \Rightarrow \mathbf{C} \Rightarrow \mathbf{D} \Rightarrow \mathbf{A}$ Unlike of lexicographical selection (selection criteria lowest price) would be selected Bidder $\mathbf{C}$.

Note: Here the selected functions are no "rapper" to them that quite so should choose. In fact, here is just an example inversely proportional to the function, to be taken for the minimization criteria and directly proportional (growing) function you need to choose the criteria for maximization - gradient type.

It should be noted that often are manifested and irregularities in the selection of "deliberate" reduction in prices (in order to get a job and later through annexes of contracts invoiced is greater), as well as to strike down the request for technical features of the bid so in the new version of the Law on public procurement you note an article of the "unusually low price" Article 92 and 93, [3].

Article 92. The contracting party may reject a bid due to the unusually low prices. Abnormally low price in terms of this Law is the offered a price that was significantly different compared to the comparable market price and 
raises doubts as to the possibility of execution of public procurement in accordance with the offered terms. If the contracting party evaluates that the bid contains an abnormally low price, he is obliged to ask the Bidder requires a detailed explanation of all its integral parts it considers relevant, in particular those concerning the economy of the construction method, production or selected technical solutions and exceptionally favorable terms that is available to the bidder for performance of the contract, or the originality of products, services or works the bidder is offering. The contracting authority is obliged that to the bidder in the case referred to in paragraph 3 of this Article, a reasonable time limit to answer. The contracting authority shall after receiving the explanation, check relevant constituent elements of the tender referred to in paragraph 3 of this Article. The contracting authority particularly verifies the fulfillment of its obligations under the applicable regulations on occupational safety, employment and working conditions, environmental protection and protection of intellectual property rights by the bidder or candidate and can request bidders from submitting appropriate evidence.

Article 93. The contracting authority may require from bidder additional explanations that will help him in the review, evaluation and comparison of bids, and can also perform control (inspection) of the bidder or its subcontractors. The contracting authority may require from the selected bidder in a competitive dialogue procedure to require confirmation of obligations accepted in the bid. The contracting authority may not demand, allow or offer a change of the bid's elements that are of significance for the application of criteria for the award of the contract, or a change whereby the bid that is inappropriate or unacceptable has made appropriate or acceptable, unless otherwise dictated by the nature of public procurement. The contracting authority may, with the consent of the bidder, to make corrections to calculation errors observed when considering the bid after the bid opening. In case of difference between unit and total price, the unit price is authoritative, if the bidder does not agree.

\section{CONCLUSION}

This proposal could be a good basis for practical application and implementation of public procurement that will meet all of the Law on Public Procurement of the required conditions: on Transparency, the ability to pre-calculate the performances of a bid by each bidder and provide the best and most acceptable bid for the company that announces a tender (bid).

It is clear that in each individual case the management of companies, which announces a competition for public procurement, it must examine the possibilities of potential bidders and to provide them with the conditions that they submit an equal bid at predefined rules.

\section{REFERENCES}

[1] Živković, M., Milosavljević, M.M., Žižović, M., Multicriteria approach to public procurement for technical sector in Serbian public companies, Fiability \& Durability Supplement no 1, Editura “Academica Brâncuşi”, Târgu Jiu, 2016.

[2] Žižović M., Živković M., Possible methodology of selecting the most favorable offer in the hydraulic devices public procurement process, Annals of the University of Oradea, Fascicle of Management and Technological Engineering, no. 2, 2016.

[3] Law on Public Procurement, Official Gazette of RS, no. 124 of 29 December 2012, 14 of 4 February 2015, 68 of 4 August 2015, p. 69.

[4] Borović, S., Nikolić, I., Multi-criteria optimization - methods, applications in logistics, software, VJ military school center, Belgrade, 1996.

[5] Milanović, D., Ranđić, D., Ristić, LJ., Selection of maintenance manager, application system to support decision-making, scientific - professional journal, Research and Design for the Economy, vol. 18, 2007, p. 7-12.

[6] Radojičić M., Žižović M., Application of multi-criteria analysis in business intelligence, University of Kragujevac Technical Faculty in Čačak, Serbia, 1998.

[7] Bobar, V., Methodology of concept application for multicriteria decision making in the public e-procurement process, Metal. Int., vol. 18, no. 4, 2013, p. 128-137.

[8] Bobar, V., Mandic, K., Suknovic, M., Bidder selection in public procurement using a fuzzy decision support system, Int. J. Decis. Support Syst. Technol., vol. 7, no. 1, 2015, p. 31-49.

[9] Csáki, C., Adam, F., Public procurement as regulated decision making problem: Challenges for DSS, Frontiers in Artificial Intelligence and Applications, vol. 212, 2010, p. 431-442. 
[10] Csáki, C., Adam, F., DSS requirements to support the regulated decision making process of public procurement, J. Decis. Syst., vol. 19, no. 4, Jan. 2010, p. 439-464.

[11] Hanski, J. Lanne, M., Hamalainen, P., Jannes, J., Three perspectives to support public decision-making and procurement of care services and technologies: learning from finnish case studies, Home Health Care Manag. Pract., vol. 27, no. 4, Apr. 2015, p. 238-246.

[12] Jin Lin, S. C., Ali, A. S., Bin Alias, A., Analytic hierarchy process decision-making framework for procurement strategy selection in building maintenance work, J. Perform. Constr. Facil., vol. 29, no. 2, Apr. 2015, p. 04014050.

[13] Love, P. E. D., Davis, P. R., Edwards, D. J., Baccarini, D., Uncertainty avoidance: public sector clients and procurement selection, Int. J. Public Sect. Manag., vol. 21, no. 7, Oct. 2008, p. 753-776.

[14] Meehan, J., Ludbrook, M. N., Mason, C. J., Collaborative public procurement: Institutional explanations of legitimised resistance, J. Purch. Supply Manag., Apr. 2016.

[15] Schneiderova Heralova, R., Life cycle cost analysis in public procurement, in CESB 2013 PRAGUE - Central Europe Towards Sustainable Building 2013: Sustainable Building and Refurbishment for Next Generations, 2013, p. 781-784.

[16] Sicakova-Beblava, E. Beblavý, M., Rozhodovanie slovenských miest o postupoch obstarávania verejných služieb, Ekon. Cas., vol. 57, no. 7, 2009, p. 667-681.

[17] Teo, P. L., Bridge, A. J., Gray, J., Jefferies, M. C., Developing a research method to test a new first-order decision making model for the procurement of public sector major infrastructure, Association of Researchers in Construction Management, ARCOM 2011 - Proceedings of the 27th Annual Conference, vol. 2, 2011, p. 715-724. 